\title{
PERCEPÇÃO AMBIENTAL DOS VISITANTES DO RECANTO DAS CIGARRAS, UMA ÁREA VERDE DA UNIVERSIDADE FEDERAL DE VIÇOSA - MINAS GERAIS
}

Juliana Provenzani de Almeida - juprovenzani@ yahoo.com.br Faculdade de Viçosa (FDV)

Anna Bárbara Gomes Mathias - barbaragmathias@yahoo.com Faculdade de Viçosa (FDV)

Isabela Mirian dos Santos Barros - isabellamsb@hotmail.com Faculdade de Viçosa (FDV)

Paloma Apolônio Rocha - paloma90rocha@ yahoo.com.br Faculdade de Viçosa (FDV)

Victória Regina Mendes - mendes.victoria@hotmail.com Faculdade de Viçosa (FDV)

Patrícia da Silva Santos - patriciasantos234@gmail.com Faculdade de Viçosa (FDV) 


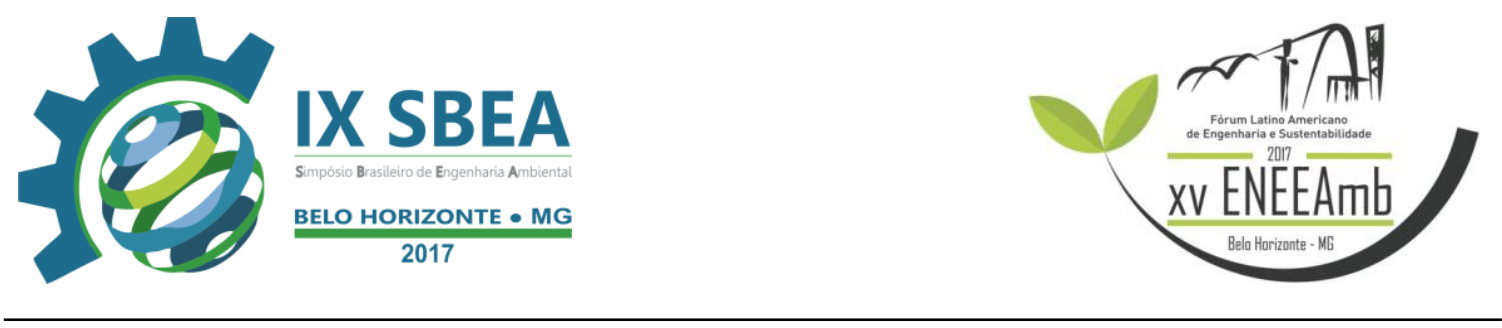

\section{RESUMO}

$\mathrm{O}$ contato com a natureza traz inúmeros benefícios à saúde humana. $\mathrm{O}$ Recanto das Cigarras, localizado no campus da Universidade Federal de Viçosa, é uma área verde que proporciona esse contato tão indispensável. Sendo um lugar de tanta importância, precisa ser valorizado e preservado, com isso, se torna necessário avaliar a percepção ambiental dos frequentadores. O objetivo deste trabalho foi avaliar a percepção ambiental dos visitantes, verificando-se os conhecimentos sobre o meio ambiente, consciência ecológica e a importância do Recanto para a comunidade em geral. Foi aplicado um questionário composto de 17 perguntas abertas e fechadas a uma amostra de 50 pessoas. A maioria dos visitantes é do sexo masculino (52\%); a maioria possui ensino médio completo (40\%) ou superior completo (25\%). Setenta e dois por cento $(72 \%)$ dos entrevistados definiram corretamente o que é meio ambiente e a maioria realiza ações de economia de luz, água e papel, no entanto, apenas $24 \%$ separa o lixo reciclável. Levando em conta o quesito segurança, $57 \%$ não se sentem seguros em visitar e $78 \%$ dos entrevistados acham que o local poderia ser mais bem utilizado pela comunidade. Alguns deram sugestões como educação ecológica, shows, visitas técnicas, atividades culturais, projetos esportivos, entre outros. É necessário um trabalho de educação ambiental para demonstrar o importante papel da área, que não é somente lazer, mas sim um local de preservação de espécies nativas, refúgio de animais e manutenção dos bens ambientais. $\mathrm{O}$ espaço poderia ser melhor utilizado em atividades pedagógicas com projetos desenvolvidos pelos vários cursos de licenciaturas oferecidos pela UFV, atendendo, assim, a uma demanda regional.

Palavras-chave: saúde, percepção, natureza.

\section{INTRODUÇÃO/OBJETIVO}

Ter contato a natureza traz muitas vantagens à saúde humana, promovendo uma melhor qualidade de vida, como destaca Amato-Lourenço et al (2016), que reflete nas áreas profissionais, emocionais, físicas, religiosas e sentimentais. Segundo um estudo realizado pela Universidade de Havard (2010), passar tempo ao ar livre traz benefícios visíveis para a saúde física e mental, como aumento dos níveis de vitamina D no organismo, diminuição do tempo de cicatrização e cura dos doentes, influencia nas 
práticas de exercícios físicos, aumenta a concentração e eleva o humor aumentando a autoestima.

É importante que pessoas de todas as faixas etárias procurem estar em contato frequente com o meio ambiente,

Pesquisas divulgadas por cientistas ingleses e finlandeses mostram que pessoas que moram perto da natureza têm uma saúde melhor do que as moradoras de locais totalmente urbanos. Os estudiosos descobriram ainda que o contato regular com o verde tem efeito a longo prazo. Mesmo após uma mudança de endereço, os benefícios da experiência permanecem durante anos (CORREIO BRAZILIENSE, 2014).

O Recanto das Cigarras, que pode ser considerado uma área verde, é um local que proporciona momentos especiais a toda a comunidade do município de Viçosa e região. Para quem deseja fugir da correria, estresse e calor do centro da cidade, essa é uma ótima opção, pois oferece contato direto com a natureza, ar puro e fresco dando prazer ao olfato e a visão, considerado um refúgio para muitas pessoas que buscam tranquilidade.

O Recanto é uma área verde de recreação, cercada de mata secundária, estruturada para festividades, piqueniques ou passeios,

Este ambiente de rara beleza faz parte de um local de pesquisa, de ensino e de lazer, aberto à visitação pública, que desperta o sentimento de bem-estar, pelo contato com a natureza. $O$ Recanto das Cigarras é um local propício para descontrair à sombra de árvores, brincar nos balanços e contemplar a natureza, tendo em vista que se encontra em uma área de mata. É um ponto importante para o convívio social no Campus da UFV, posto que frequentemente é usado para confraternizações, como churrascos de formatura e solenidades de entrega de prêmios para funcionário da UFV (LADEIRA et al., 2001).

A área é um local de inúmeras vantagens: constitui em importante instrumento para a regulação do clima de Viçosa, como a manutenção da biodiversidade, controle de 


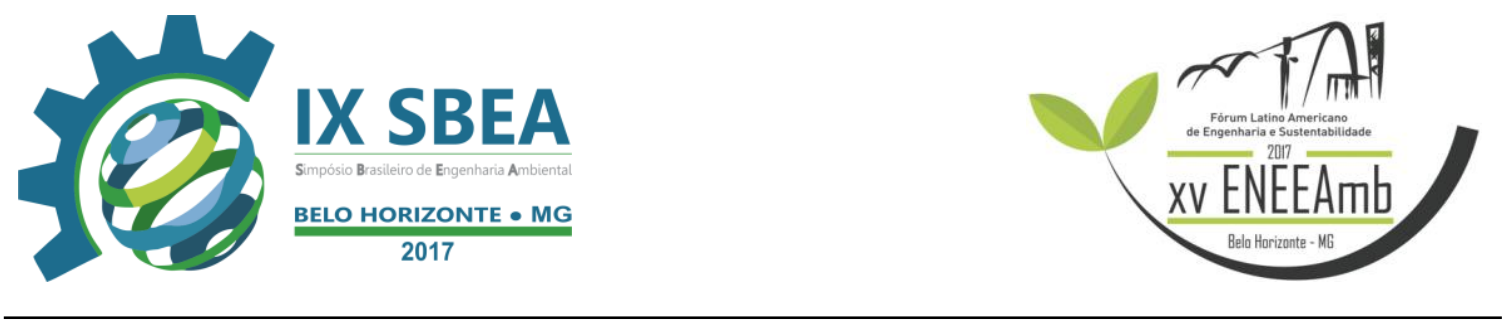

poluição, aspectos paisagísticos, além de influenciar diretamente nos aspectos físicos e psicológicos dos cidadãos viçosenses, devendo ser valorizado e preservado.

Considerando o fato de não haver estudos que apontem a percepção dos frequentadores, o objetivo deste é avaliar a percepção ambiental dos visitantes, verificando-se os conhecimentos sobre o meio ambiente, consciência ecológica e a importância do Recanto para a comunidade em geral.

\section{METODOLOGIA}

O Recanto das Cigarras está localizado na cidade de Viçosa, Zona da Mata Mineira, no campus da Universidade Federal de Viçosa e é um local de fácil acesso, o que favorece sua visitação. É muito frequentado por estudantes e pela sociedade, que usam o local para encontros de amigos, aniversários, caminhadas e passeios em geral.

Para a realização da pesquisa foi aplicado um questionário semi- estruturado composto de 17 perguntas abertas e fechadas (Anexo 1) a uma amostra de 50 visitantes do Recanto das Cigarras, considerando a faixa etária acima de 15 anos (critério de inclusão). $\mathrm{O}$ questionário foi dividido em perguntas que avaliaram o perfil do entrevistado, seu conhecimento ambiental e consciência ecológica e sobre a sua percepção em relação ao Recanto.

A abordagem foi realizada em um fim de semana do mês de outubro de 2016, com a apresentação e identificação das alunas, demostrando a importância da atenção do entrevistado na contribuição para a realização e execução do presente trabalho. Os entrevistados foram instruídos a não responderem próximos a pessoas que pudessem influenciar as respostas dos mesmos, garantindo assim a confiabilidade/objetividade das respostas.

A análise dos dados foi feita por meio da estatística descritiva e estatística inferencial, através do teste Qui Quadrado $\left(\chi^{2}\right)$, baseado em hipóteses, em que são verificadas se existem diferenças estatísticas entre os dados observados e os dados esperados. Foi adotado nível de significância 5\% de probabilidade.

\section{RESULTADOS E DISCUSSÃO}




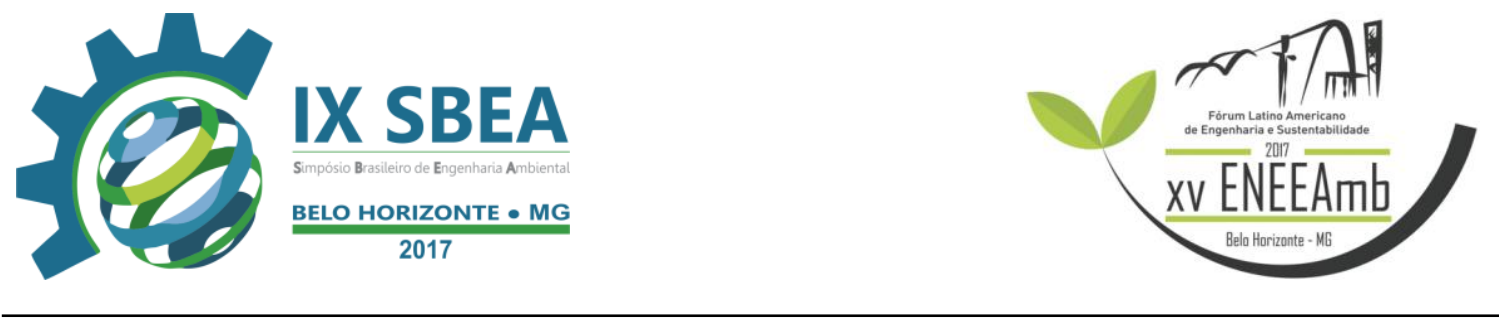

Quanto ao perfil dos entrevistados, $52 \%$ são do sexo masculino e $76 \%$ residem em Viçosa (Figura 1). A maioria dos entrevistados tem faixa etária entre 21 a 25 anos, correspondendo a $30 \%$ do total, $24 \%$ entre 15 a 20 anos, $14 \%$ entre 26 a 30 anos, $18 \%$ entre 31 a 35 anos, $8 \%$ entre 36 a 40 anos, e 2\% entre as faixas de 41 a 45 anos, 51 a 55 anos e 61 a 65 anos. O nível de escolaridade observado foi de 6\% para aqueles que cursaram o ensino fundamental completo, $2 \%$ ensino médio incompleto, $40 \%$ ensino médio completo, $17 \%$ ensino superior incompleto, $25 \%$ ensino superior completo, $2 \%$ mestrado e $4 \%$ para aqueles que cursaram doutorado e pós-graduação.

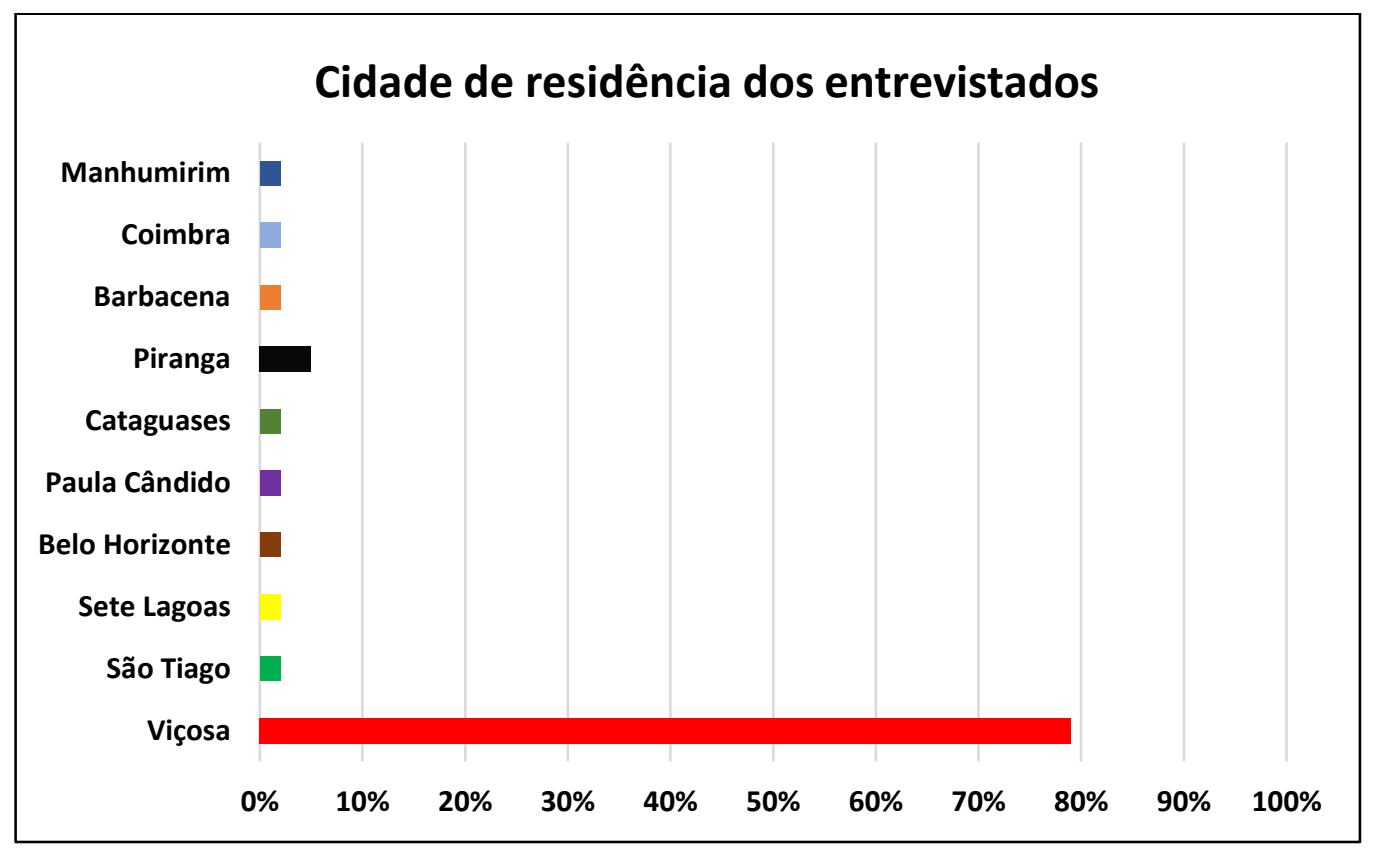

Figura 1. Cidade de residência dos entrevistados durante o trabalho de percepção ambiental do Recanto das Cigarras, UFV, Viçosa, Minas Gerais.

Em relação ao conhecimento e consciência ecológica, 96\% dos entrevistados não participam de nenhum projeto ambiental (diferença significativa com $\chi^{2}$ calculado de $42,32$ com $\mathrm{p}=0,05)$. A maioria dos entrevistados $(72 \%)$ soube definir corretamente o que é meio ambiente. Do total de entrevistados, $86 \%$ desligam as luzes e ventiladores ao saírem da sala; $62 \%$ desligam o monitor do computador quando fazem uma pausa para descanso; $86 \%$ fecham a torneira da pia do banheiro para escovar os dentes; $20 \%$ utilizam papel reciclado nas suas impressões e/ou rascunhos; $54 \%$ imprimem ou fazem 


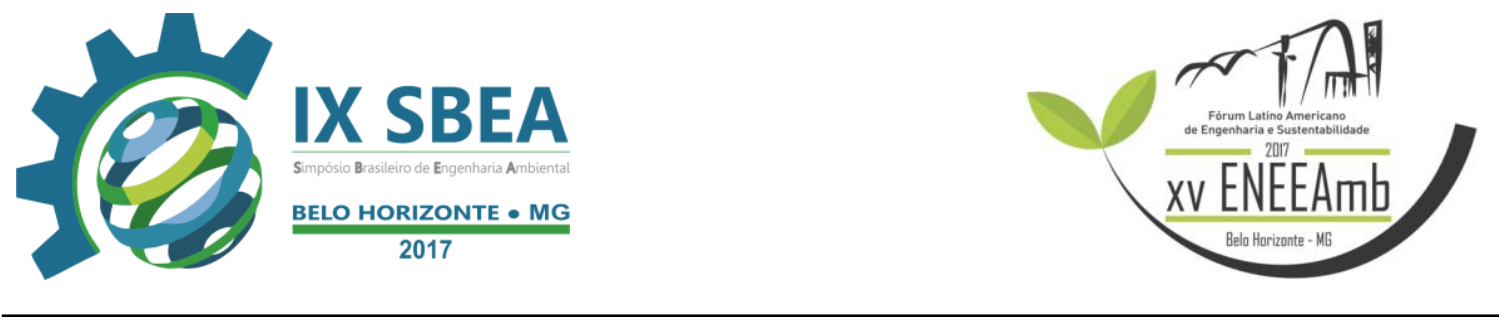

cópia da maioria dos documentos em frente e verso. Por outro lado, apenas $24 \%$ separam o lixo reciclável e $48 \%$ reutilizam a água da máquina (Figura 2).

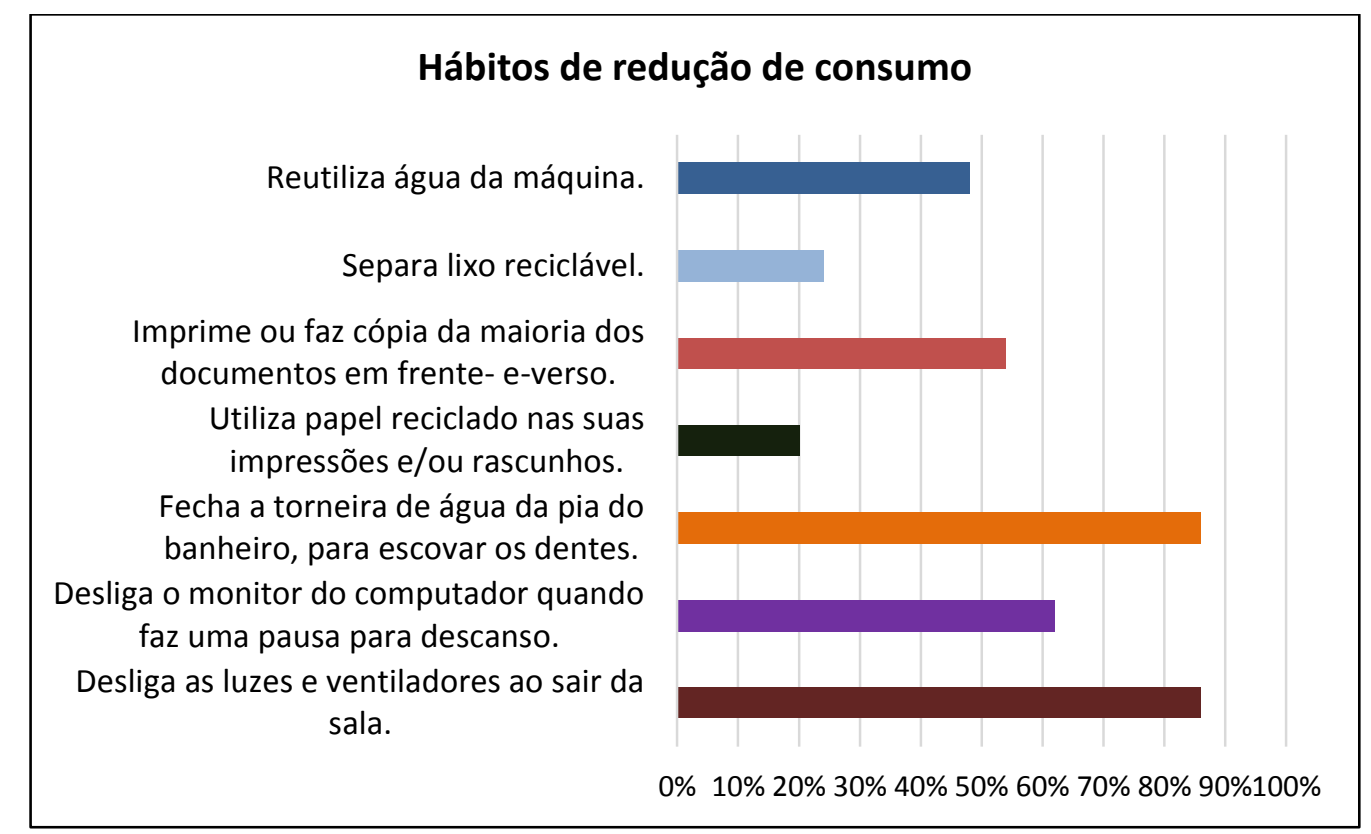

Figura 2 - Hábitos de redução de consumo realizados pelos entrevistados durante o trabalho de percepção ambiental do Recanto das Cigarras, UFV, Viçosa,

Minas Gerais.

Quando perguntados se concordam com a fiscalização e punição para quem não cuida do meio ambiente, $100 \%$ dos entrevistados disseram que são a favor.

As questões $8,9,10,11,12,14,15,16$ e 17 do questionário referem-se à percepção dos visitantes em relação ao Recanto. Quando questionados sobre o motivo da visita, $92 \%$ disseram para lazer, $4 \%$ para trabalho e os outros $4 \%$ para estudo. Do total, 39\% visitam com frequência devido ser um lugar tranquilo e agradável, $61 \%$ não visitam com frequência, alegando falta de tempo. Todos os entrevistados consideram o Recanto um lugar para se ter contato com a natureza, porém $34 \%$ não o consideram limpo e bem cuidado.

Levando em conta o quesito segurança, $57 \%$ não se sentem seguros em visitar e $78 \%$ dos entrevistados acham que o local poderia ser melhor utilizado pela comunidade. 


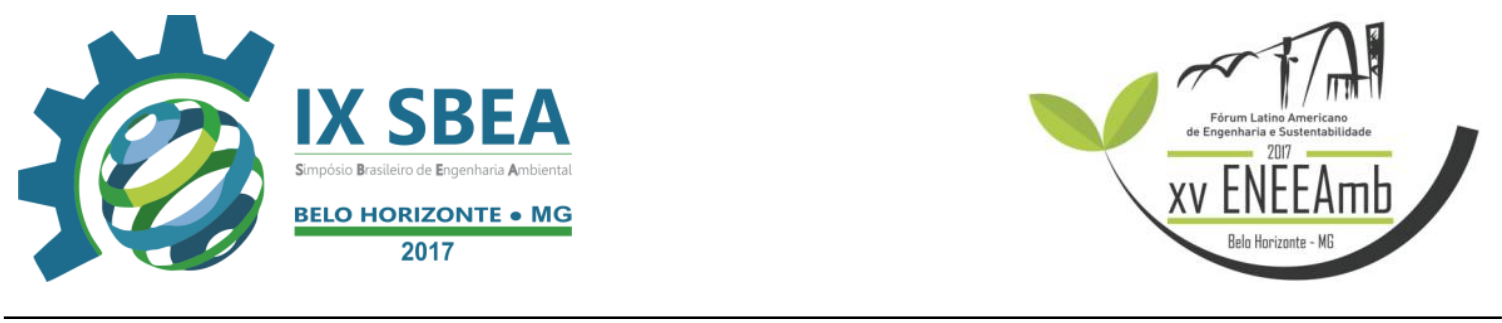

Alguns deram sugestões como educação ecológica, shows, visitas técnicas, atividades culturais, projetos esportivos, entre outros.

A maioria (83\%) considera o Recanto das Cigarras um local muito bom para passear com a família, ter contato com a natureza e com um enorme potencial, enquanto $17 \%$ o consideram razoável.

Foram sugeridas por $85 \%$ das pessoas que participaram da pesquisa, algumas sugestões para melhoria do Recanto. A principal foi o aumento da segurança e outras, como melhoria na limpeza e aumento das lixeiras, infraestrutura, atividades voltadas para o conhecimento das espécies de flora e fauna do local, reflorestamento, bebedouros e fiscalização para evitar o uso de drogas.

Submetidas ao teste $\chi^{2}$, foi verificado que nas questões 9,12 e 14 não existem diferenças estatísticas entre os dados observados e esperados, aceitando a hipótese nula, já nas questões 10, 11 e 15 houve diferenças estatística entre os dados, rejeitando a hipótese nula.

\section{CONCLUSÕES/RECOMENDAÇÕES}

O Recanto das Cigarras é uma área de lazer importante regionalmente. A grande variedade de níveis de escolaridade e faixas etárias pode estar associada à localização da área, dentro do campus da UFV.

A maioria dos entrevistados sabe definir bem o que é meio ambiente e concordam com a punição para aqueles que não preservam, porém apenas $4 \%$ do total participam de algum projeto ambiental.

O local é visto principalmente como uma área de lazer, não tendo os visitantes a percepção da importância ambiental da área. Todos os entrevistados o consideram um ótimo lugar para se ter contado com a natureza. Concluiu-se que grande parte dos visitantes não se sente seguros na área e acham que o Recanto poderia ser melhor utilizado pela sociedade.

As opiniões sobre o Recanto são boas, porém foram sugeridas várias ações para sua melhoria, a principal foi o aumento da segurança e da limpeza, diante disto, é preciso haver uma mobilização por parte dos responsáveis. 
É necessário um trabalho de educação ambiental para demonstrar o importante papel da área, que não é somente lazer, mas sim um local de preservação de espécies nativas, refúgio de animais e manutenção dos bens ambientais.

O espaço poderia ser melhor utilizado em atividades pedagógicas com projetos desenvolvidos pelos vários cursos de licenciaturas oferecidos pela UFV, atendendo, assim, a uma demanda regional. 


\section{PERCEPCÄO AMBIENTAL DOS VISITANTES DO RECANTO DA CIGARRA-ANO 2016}

1) Sexo: $\square \mathrm{F} \quad \square \mathrm{M}$

02) Idade:

03) Estudou até qual série?(grau de escolaridade)

04) Cidade onde mora?

05) Você participa de algum projeto ambiental?

\section{SIM $\square$ NAO}

Se sim, qual?

06) $\mathrm{O}$ que você entende por meio ambiente?

07) Em casa você habitualmente:

( ) Desliga as luzes e ventiladores ao sair da sala.

( )Desliga o monitor do computador quando faz uma pausa para descanso.

( )Fecha a torneira de água da pia do banheiro para escovar os dentes.

( )Utiliza papel reciclado nas suas impressões e/ou rascunhos.

( ) Imprime ou faz cópia da maioria dos documentos em frente-e-verso.

( ) separa o lixo reciclável.

( ) reutiliza a água da máquina.

08) Qual o motivo da visita no Recanto das Cigarras?
9) Visita com muita frequência?

$\square \operatorname{sIM} \square$ NÃO

Por quê??

10) Você considera o Recanto um lugar importante para se ter contato com a natureza?

$$
\text { SIM } \square \text { NÃO }
$$

11)Você acha o recanto um lugar limpoe bem cuidado?

IIM $\square$ NÃO

12) Você conhece alguma espécie exótica do Recanto? $\square \operatorname{sIM} \square$ NÃo

Qual?

13) Você concorda com a fiscalização $e$ punição para quem näo preservar (cuidar) o meio ambiente?

$\square \operatorname{SIM} \square$ NÃO

14) Você se sente seguro no Recanto ?

$\operatorname{SIM} \square$ NÃO

15) Você acha que o Recanto poderia ser melhor utilizado pela comunidade?

$\square \operatorname{SIM} \square$ NÃO

Se sim, como?

16) Qual a sua opiniäo sobre o Recanto?

17) Alguma sugestão para melhorar o recanto?

Anexo 1 - Questionário aplicado aos frequentadores do Recanto das Cigarras, UFV em outubro de 2016. 


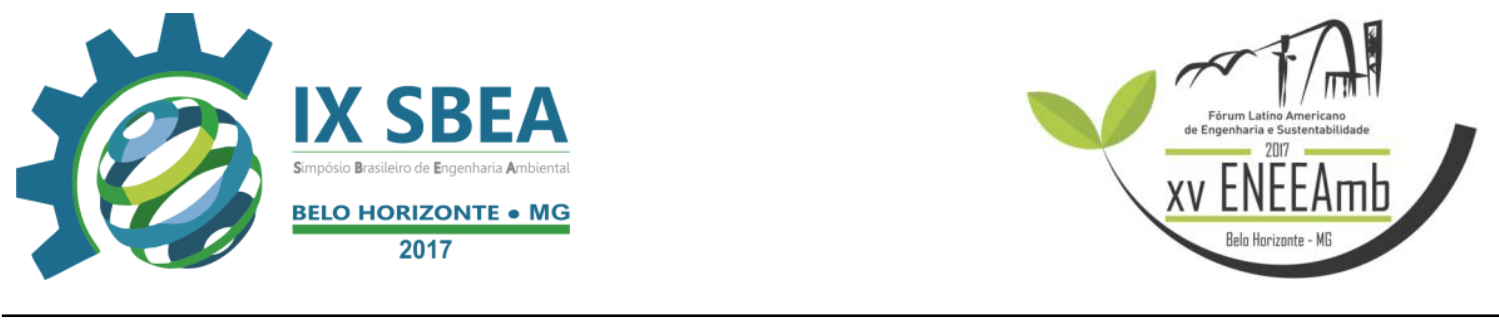

\section{REFERÊNCIAS BIBLIOGRÁFICAS}

AMATO-LOURENÇO et al. Metrópoles, cobertura vegetal, áreas verdes e saúde. Estudos Avançados, USP, São Paulo, v. 30. n. 86, p. 113- 130. 2016.

CORREIO BRASILIENSE. Estudo revela que morar perto da natureza melhora a saúde física e mental. Correio Braziliense, Brasília, 28 janeiro 2014. Ciência e Saúde. Disponível em: http://www.correiobraziliense.com.br/app/noticia/ciencia-esaude/2014/01/28/interna_ciencia_saude,409955/estudo-revela-que-morar-perto-danatureza-melhora-a-saude-fisica-e-mental.shtml. Acesso em: 07 maio 2017.

HAVARD. A prescription for better health: go alfresco. Havard Health Publications, Boston,

july 2010. Harvard Health Letter. Disponível em: http://www.health.harvard.edu/newsletter_article/a-prescription-for-better-health-goalfresco. Acesso em: 14 maio 2017.

LADEIRA, A. et al. Proposição de roteiros turísticos para o Município de ViçosaMG. Revista Árvore, Viçosa,v. 25, n. 4, p. 527, 2001. 